\title{
O TRABALHO DOCENTE E A INCLUSÃO ESCOLAR: IMPACTOS E MUDANÇAS EM SALA DE AULA
}

\section{TEACHERS WORK AND SCHOOL INCLUSION: IMPACTS AND CHANGES IN THE CLASSROOM}

\author{
Alda Junqueira Marin* \\ Rosimeire Maria Orlando Zeppone ${ }^{* *}$
}

\begin{abstract}
Resumo: Este estudo tem como foco problematizar alguns impactos da política de inclusão escolar no trabalho de professoras das séries iniciais do ensino fundamental. Seu objetivo é descrever e analisar situações de sala de aula para compreensão de aspectos pedagógicos detectados com auxílio de questionários, entrevistas e observações em abordagem de cunho etnográfico. Os dados obtidos foram analisados por meio da categoria teórica de habitus, proposta por Bourdieu (1989), e das categorias ação e prática, conforme delimitadas por Gimeno (1998). Foi possível identificar impactos iniciais das políticas e mudanças organizadas ao redor de algumas chaves de análise selecionadas para este artigo: procedimentos para ensinar, aprender, avaliar e dinâmicas de socialização. A hipótese inicial orientadora do estudo foi comprovada, pois a inclusão escolar de alunos com deficiência no ensino regular das redes de ensino causa impactos diferenciados no trabalho dos professores. Em face de disposições presentes em seus habitus, as professoras iniciaram seu trabalho com as práticas entendidas como disposições culturais presentes nas escolas instaladas para o trabalho com crianças sem deficiência. Gradativamente passaram a ter ações diferenciadas entre elas, mas alterando seus procedimentos para ensinar de modo que todas as crianças passassem a aprender e para avaliá-las, assim como tomaram providências para novas necessidades de dinâmicas de socialização entre as crianças, apesar do acúmulo de trabalho e das condições precárias.
\end{abstract}

Palavras-chave: Educação Especial. Políticas de Inclusão Escolar. Trabalho Docente.

Abstract: This study focuses on discussing some impacts of the inclusion policy in the work of school
teachers of initial grades of elementary school. It aims at the description and analysis of classroom
situations to understand pedagogical aspects detected with the aid of questionnaires, interviews and
observations in an ethnographic approach. The obtained data were analyzed by means of the theoretical
category habitus, proposed by Bourdieu (1989) and categories of action and practice, as bounded by
Gimeno (1998). It was possible to identify initial impacts of policy changes and organized changes
around a few key analysis selected for this presentation: procedures for teaching, learning, rate and
dynamics of socialization. The initial hypothesis guiding the study was confirmed, because the school
inclusion of students with disabilities in the mainstream of education networks causes differentiated

${ }^{*}$ Doutora em Ciência Educação pela UNESP. Professora da Pontifícia Universidade Católica de São Paulo. Programa de Estudos Pós-Graduados em Educação, História, Política, Sociedade. E-mail: <aldamarin@pucsp.br>

* Doctor in Science Education from UNESP. Professor at the Catholic University of São Paulo. Postgraduation programme in Education, History, Politics, Society. E-mail: <aldamarin@pucsp.br>

** Doutora em Educação Escolar pela UNESP. Professora temporária da Universidade Federal de São Carlos. Departamento de Psicologia. E-mail: <mzeppone@gmail.com>

${ }^{* *}$ Doctor in School Education from UNESP. Temporary Professor at the Federal University of São Carlos. Psychology Department. E-mail: <mzeppone@gmail.com> 
impacts to the work of teachers. Face to these provisions present in their habitus, the teachers began their work with extended practices such as cultural dispositions present in the schools established to work with children without disabilities. Gradually, they started to have different actions among them, but changing its procedures to teach so that all children could learn and to evaluate them, as well as they took measures to the needs for the dynamics of socialization among children, despite the accumulation of work and poor conditions.

Keywords: Special Education. School Inclusion Policy. Teaching Work.

\section{Introdução}

No Brasil, importantes prescrições em vigência desde a década de 1980, como, por exemplo, a Constituição Federal (BRASIL, 1988), a nova LDB 9394/96 (BRASIL, 1996), as Diretrizes Nacionais para a Educação Especial na Educação Básica (BRASIL, 2001), a Política Nacional de Educação Especial na Perspectiva da Educação Inclusiva (BRASIL, 2008), entre outros documentos, trazem, no plano formal, regulamentações relativas à educação nacional e, mais especificamente, à inclusão escolar dos alunos com deficiência nas redes regulares de ensino.

Dentre as inúmeras esferas de atuação política presentes nessa documentação, o que interessa aqui é a esfera relacionada ao trabalho dos professores. Essa foi a preocupação central de uma pesquisa de onde se originaram os dados do presente artigo, ou seja, a problematização de alguns aspectos pedagógicos por meio do estudo do trabalho docente em face do impacto da ação política educacional de inclusão de alunos com deficiência no ensino regular.

A pesquisa, já concluída, teve como objetivo a busca de verificação do impacto dessa ação política em sala de aula e a compreensão da atuação das professoras. Foi realizada em uma cidade do interior de São Paulo, em salas de aula de $1^{\mathrm{a}}, 2^{\mathrm{a}}$ e $4^{\mathrm{a}}$ séries do ensino fundamental. Com orientação de pesquisa de cunho etnográfico (WOODS,
1998) foram realizadas observações em salas de aula, respondidos questionários e feitas entrevistas com as professoras, obtendo-se dados fundamentais em situações nas quais havia alunos com deficiência, participantes do processo de inclusão escolar.

O recorte da pesquisa relatada neste texto se estrutura em duas partes principais: na primeira estão alguns conceitos utilizados para análise dos dados e na segunda estão os dados relacionados à esfera pedagógica, ao ensino, em que ocorriam, e ainda ocorrem, impactos decorrentes do processo de inclusão, aqui analisados, apontando mudanças em aspectos pedagógicos a favor das crianças.

\section{O trabalho docente e a inclusão}

Como um dos documentos mais importantes e de ampla repercussão, a Declaração de Salamanca (1994) aponta, com destaque mundial, a existência de pessoas com diferentes necessidades especiais a serem abrigadas pelas escolas, incluindo milhões de pessoas com deficiência que "carecem de rudimentos duma educação básica” (ESPANHA, 1994, p.13). Destaca que 200 milhões de crianças em todo o mundo não tinham, na época, acesso à educação, e que um número considerável dessas crianças apresentavam 
deficiência, evidenciando o velho entrave educacional que é a democratização do ensino fundamental. Antigos problemas de acesso, permanência e qualidade da escola pública marcam, ainda hoje, a realidade da escola brasileira, que vem convivendo com essa exigência da inclusão escolar dos alunos com deficiência no ensino comum. (BUENO, 1999; BUENO, MENDES e SANTOS, 2008; MENDES e ALMEIDA, 2010; SOARES, 2006).

Atualmente, as prescrições oficiais brasileiras adentram os portões escolares, impondo o desafio da inclusão de alunos com deficiência no ensino comum. É uma proposta que vem sendo tanto questionada, criticada e repensada por uns, como, por exemplo, Schwartzman (1997) e Bueno (1999), quanto defendida por outros, entre estes Mantoan (1997) e Sassaki (1997). Apresenta-se, assim, como uma área de estudos com conflitos e tensões, dentre os quais os de verificação de suas possibilidades e limites.

De qualquer forma, as alterações via prescrições oficiais estão sendo implantadas e vivenciadas no âmbito escolar. Como frisa Viñao Frago (1996), ao abordar as relações entre a escola e a sociedade, no que tange a reformas e inovações, as instituições escolares mudam, podendo agrupar-se sob a denominação de culturas escolares. Essas alterações são, entre outras possibilidades, a combinação de tradição e mudança, consequência de decisões relativamente limitadas por fatores externos, condicionantes tecnológicos e uma série de práticas sedimentadas no tempo.

O referido autor tece, também, comentários sobre os professores, falando sobre a cultura na atuação docente. Quando pontua sobre a cultura partilhada pelos professores, considerada como a combinação das crenças, mentalidades, hábitos e práticas, gerada e compartilhada coletivamente por um conjunto de professores, ao longo de tempo, frisa que essa cultura sofre impacto a cada reforma educacional. Ou seja, cada nova proposta constitui pressões e exigências que acarretam efeitos na combinação citada.

Esse mesmo autor nos permite compreender que a aplicabilidade desses preceitos legais presentes nas prescrições oficiais, ou seja, nas ações políticas de alterações, como as de inclusão escolar, constitui um processo complexo, que resulta em impactos e mudanças em toda a trajetória até chegar às professoras, entre as quais podemos incluir as observadas na pesquisa. E quando ocorre esse encontro, na maioria das vezes não acontece de maneira tranquila ou passiva, pois nas realidades sociais, incluindo a escola, há situações de choques com o existente.

Nesse contexto de ocorrência da pesquisa, há que se considerar a complexidade do trabalho do professor, que é a figura central da atividade de ensinar, como conceitua Marin (2005). No contexto escolar o ensino conjuga várias ações e

(...) se configura, portanto, como o trabalho executado pelo professor para dar conta do ensino; tal atividade se mostra, desde logo, como trabalho extremamente complexo, ponto de convergência de questões práticas do processo educativo, considerado este nas suas mais variadas dimensões de análise (MARIN, 2005, p. 37).

Focalizado para atender crianças, esse contexto de ensinar - em geral a sala de aula - abrange ações de planejar, as quais implicam a definição de objetivos, assuntos e temas dos vários componentes curriculares, promovem a busca e seleção de materiais. A partir de considerações sobre as características da classe de alunos, há necessidade 
de organizar e selecionar os procedimentos e as tarefas e avaliações, entre as atribuições mais comuns dos professores. Mas esse contexto, ao sofrer as inúmeras influências da organização escolar e de fora dela, sofre as injunções das ações políticas educacionais, como, neste caso, as decorrentes das definições sobre a inclusão de crianças com deficiências. Nesse conjunto, este artigo abrange, sobretudo, procedimentos para ensinar, aprender, avaliar e promover a socialização.

É possível, portanto, identificar uma interferência no trabalho do professor quando se altera significativamente a composição da turma de alunos inserindo crianças com deficiência. Essa circunstância de heterogeneidade, após a expansão da escolaridade para toda a população, ainda não é digerida pelo professorado, pois o que vigora nas escolas é a busca da homogeneidade, traço extremamente forte da cultura escolar (FERREIRA, 2002).

Contribuindo para descrever e explicar o desempenho docente nessas mudanças, compreendendo a inclusão de alunos com deficiência em sala de aula comum, foi possível localizar em Bourdieu (1989) o conceito importante de habitus, ou seja, as maneiras pelas quais as estruturas sociais se organizam tanto em nossas cabeças como em nossos corpos, pela interiorização da exterioridade (modos de perceber, sentir, pensar e agir vigentes no espaço social) quanto pela exterioridade do interior, ou seja, manifestando modos de percepção, expressão, sentimento e ação adquiridos anteriormente.

Corcuff (2001, p. 53), por sua vez, ao analisar a sociologia de Pierre Bourdieu, complementa as informações sobre o conceito de habitus, afirmando que:

(...) é constituído por 'princípios geradores', ou seja, um pouco como um programa de computador (mas um programa em parte auto-corretivo), ele é levado a dar múltiplas respostas a diversas situações encontradas, a partir de um conjunto limitado de esquemas de ação e de pensamento. Assim ele reproduz mais quando é confrontado com situações habituais e pode ser levado a inovar quando se encontra diante de situações inéditas.

Sempre presentes nas subjetividades, tais estruturas sociais constituem-se, inicialmente, por meio das primeiras experiências, que Bourdieu (1989) denomina de habitus primário.

O habitus primário é a base de todo o desenvolvimento do habitus adquirido no grupo social mais próximo, especialmente a família, o grupo de pares; já o habitus secundário é formado pelas situações posteriores, tendo a escola como uma forte presença desde a mais tenra infância.

Pensandonessa direção, com Bourdieu, Bonnewitz (2003) colabora para a compreensão quando ressalta que o habitus é, portanto, uma estrutura interna que continuamente se ajusta, pois, apesar de atuar como princípio de conservação, essa estrutura pode tornar-se um mecanismo de invenção e, consequentemente, de mudança.

É possível verificar, então, refletindo sobre esse conceito, que as ações docentes decorrem de um longo processo iniciado na família, perpassado pelas demais inserções até chegar às atividades desenvolvidas no interior da escola, em um processo de socialização/formação contínua. E, ao longo desse percurso, são múltiplas as interferências que levam todos os sujeitos a adquirir e alterar diversas disposições e a incorporá-las, constituindo os seus habitus alterados.

Nesse conjunto de incorporações de disposições estão as relativas aos modos de pensar, sentir e agir ligados às questões enfrentadas por todos, incluindo-se as 
questões sobre as pessoas com deficiência, constituidoras dos habitus iniciados na família e constantemente reforçados ou alterados ao longo da vida.

Complementando tais conceitos e, de certo modo, articulando-os, Gimeno (1998) nos auxilia diferenciando os conceitos de ação e prática. Considera como prática na educação a cultura compartilhada por aqueles que vivenciam a educação escolar, aquelas estruturas já criadas e em funcionamento quando as ações rotineiras do grupo dos professores chegam à consolidação de padrões sedimentados, à cristalização coletiva da experiência. Para tanto se vale, também, do conceito de habitus. As ações são consideradas como as possibilidades de subjetividade, de alteração do que encontram, constituindo uma dupla lógica, fundamental para a compreensão do que ocorre nesses momentos de implantação de novas ações políticas no interior da escola.

Diferentes pesquisas, desde o início da década de 1990, têm identificado estranhamento por parte dos professores, diante da nova situação e desafios que se apresentam para a educação de crianças com deficiência, sobretudo agora com as decisões de inclusão escolar desse alunado em sala comum (OLIVEIRA, 1996, 2005; LUNARDI, 2005; SILVA, 2003; SOARES, 1990;), situação verificada também na pesquisa aqui relatada. No entanto, percebeu-se, desde os primeiros contatos com classes que possuíam crianças incluídas, que as professoras se manifestavam de modo diverso, apresentando-se, assim, a faceta das subjetividades dentro dos modos possíveis. Tal detecção levou à problematização da situação. É certo que a instituição constitui-se de sujeitos também históricos, vinculados a relações concretamente dadas. Mas, quais, efetivamente, são as consequências desencadeadas no trabalho docente pela política de inclusão escolar?
Como operam os professores a partir da chegada de alunos com deficiência em suas turmas? Qual o impacto das ações políticas de inclusão no trabalho docente, no ensino, que é o seu núcleo central?

\section{O lócus de pesquisa e alguns dados}

A pesquisa foi realizada em escolas de ensino fundamental que, no estado de São Paulo, desde 1998, passaram a se organizar como ciclos, denominando-se as quatro séries iniciais como Ciclo I. As escolas que permitiram acesso foram, respectivamente, as responsáveis pelas $1^{\mathrm{a}}, 2^{\mathrm{a}}$ e $4^{\mathrm{a}}$ séries, anteriores à implantação da escola de nove anos.

Em seus pontos comuns, as três escolas têm como fonte mantenedora o Governo do Estado de São Paulo, sendo administradas pela Secretaria de Estado da Educação, com supervisão da Diretoria de Ensino (órgão regional), e regidas com base nos dispositivos constitucionais vigentes na Lei de Diretrizes e Bases da Educação Nacional e no Estatuto da Criança e do Adolescente. São, portanto, sujeitas aos mesmos processos e determinações.

Em suas diferenças estão os lugares de sede na cidade: 1 ) parte central, arquitetura antiga, dois pavimentos, considerada "boa escola”; 2) um dos primeiros bairros da cidade, arquitetura antiga, considerada com “bom ensino” pela população; 3) bairro afastado do centro, construção nos moldes das últimas décadas do século XX, portanto térrea com blocos interligados. As três turmas tinham cerca de 30 alunos cada e professoras com formação em curso de magistério, duas delas com curso superior, uma com 20 anos, outra com 10 e a terceira com 21 anos de experiência no ensino. Duas dessas professoras tinham, também, um ou dois anos de experiência com crianças com deficiência. 
Nessas escolas estavam com tais professoras, respectivamente, crianças com deficiência, a saber: 1) um aluno com diagnóstico de deficiência intelectual, 12 anos, $2^{\mathrm{a}}$ série (atual $3^{\circ}$ ano); 2) uma aluna com quadro de paralisia cerebral, 11 anos, $1^{\mathrm{a}}$ série (atual $2^{\circ}$ ano); 3) uma aluna com deficiência auditiva bilateral de grau severo, $4^{\mathrm{a}}$ série (atual $5^{\circ}$ ano).

Quando questionadas sobre as mudanças que vinham ocorrendo no interior das escolas, percebeu-se que tais ações políticas pareciam realmente impactar as professoras, mesmo no caso daquelas que já haviam tido alunos com características de deficiência em suas salas de aula.

A partir dos dados obtidos, foi possível verificar impactos sobre o trabalho docente das professoras, em geral não formadas para atuar com tal heterogeneidade e socializadas em contextos sociais e escolares em que tais crianças, até pouco tempo, eram segregadas em instituições e classes especiais pouco afeitas ao ensino e aprendizagem de conteúdos escolares (SOARES, 1990; BUENO, 2004).

Foram selecionadas duas chaves de análise, apesar de termos diferentes esferas pedagógicas em que ocorrem impactos, tanto no trabalho das professoras quanto nos espaços escolares em que foram percebidos efeitos e reações relativos ao processo de inclusão, não abordados neste trabalho.

As chaves de análise emergiram das inúmeras leituras do material: a) procedimentos para ensino preocupados com aprendizagem e avaliação; e b) dinâmicas de socialização.

\section{Procedimentos para ensino, aprendizagem e avaliação}

Os procedimentos para ensino, aprendizagem e avaliação - aspectos centrais nas escolas - sofreram fortes impactos.

As professoras atuavam sob o padrão cultural das escolas, com procedimentos que visavam a atender a crença no princípio da homogeneidade do alunado. Alguns excertos das entrevistas e dos registros do caderno de campo com as observações realizadas nas salas de aula são representativos dessa perspectiva:

"Ele faz a mesma atividade que os outros alunos." (PROFESSOR 1)

"Se elogio, faço igualmente para todos. Se preciso chamar a atenção, também o faço." (PROFESSORA 1)

"Eu não sei como avaliar esta criança." (PROFESSORA 3)

"Eu quero ajudar, mas não consigo, não sou especialista.” (PROFESSORA 3)

"Eu tenho que dar o conteúdo e não consigo, o SARESP ${ }^{1}$ está aí.” (PROFESSORA3)

A professora 1, que tinha um aluno com deficiência intelectual em sua sala, tentou mostrar que o aluno incluído era como os demais. A professora 3, que atendia uma aluna com deficiência auditiva, atuava com ela da mesma forma que com os demais alunos: chamava-os até sua mesa, embora tivesse muita dificuldade de se comunicar com essa aluna e estivesse bem preocupada com o seu ensino e avaliação, pois percebeu que o

\footnotetext{
${ }^{1}$ O SARESP (Sistema de Avaliação do Rendimento Escolar do Estado de São Paulo), é uma avaliação aplicada pela Secretária da Educação do Estado de São Paulo para alunos da rede estadual de ensino que estão na $2^{\mathrm{a}}, 4^{\mathrm{a}}, 6^{\mathrm{a}}$ e $8^{\mathrm{a}}$ série do Ensino Fundamental, e $3^{\circ}$ ano do Ensino Médio.
} 
procedimento pedagógico a ser utilizado teria que ser diferente do costumeiro.

Esses são exemplos de manifestações docentes, ao lado dos procedimentos rotineiros de explicação coletiva da matéria, copiar cabeçalho da lousa, escrever o ponto na lousa para os alunos copiarem, fazer ditado de frases, leitura coletiva de palavras da lousa, entre outras atividades de ensino e aprendizagem. Tais exemplos constituem as práticas, ou seja, a atuação sedimentada, rotineira, cristalizada na história da escola, compondo padrões na cultura que se transmite e se recria (GIMENO, 1998), constantemente, a partir de habitus partilhados com base na lógica homogeneizadora de nossa escola.

Essa mesma prática docente, entretanto, foi impactada no sentido de que as professoras percebiam que os procedimentos que vinham utilizando já não bastavam para suprir a nova situação. Devagar, elas passaram a mesclar o atendimento homogêneo que anteriormente dispensavam para a classe com um atendimento mais individualizado.

Alguns excertos de manifestações registradas são exemplificadores de tais percepções:

"Eu não fiquei chateada e nem com medo, eu só fiquei insegura quanto ao meu trabalho, como eu vou fazer para lidar com esse problema, mas eu enfrentei, eu falei: vou ver o que dá para fazer." (PROFESSORA 1)

"A mesma atividade que eu dou para os outros eu dou para ela também, só que a dela de uma maneira diferenciada." (PROFESSORA 2)

"Eu procuro trabalhar diferente, trazer coisas diferentes de casa." (PROFESSORA 1)

"Vamos mocinha, tem que terminar a atividade.” (PROFESSORA 2)
"É para ela não se sentir atrasada, assim ela copia” (PROFESSORA 3)

Verifica-se o atendimento das professoras às condições dos alunos, procurando atividades diversificadas, levando em consideração o ritmo dos alunos, suavizando o tom de voz para se dirigir aos alunos incluídos, percebendo os limites cognitivos da aluna com paralisia cerebral, que um dia reconhece a letra A e no dia seguinte não reconhece letras nem números. Chamamos a atenção para as subjetividades, principalmente por termos verificado a diversidade de ações propostas pelas professoras, pois cada uma manifestou-se de forma diferenciada da outra, mas todas apontando as mudanças ocorridas em seu trabalho após a entrada dos alunos especiais na sala de aula.

O impacto foi ainda maior quando foram analisados os depoimentos das professoras ao dizerem que aprenderam com a situação, pois passaram a solicitar a participação de todos os alunos, fazendo perguntas todo o tempo enquanto passavam as atividades na lousa, pedindo explicações. Perceberam a necessidade de alterar os procedimentos para ensinar, de modo que as crianças aprendessem, dando mais tempo para os diálogos, percebendo de modo mais claro e constante as dificuldades das demais crianças a partir das dificuldades identificadas nas crianças incluídas e, com isso, alterando também o modo de avaliar todas as crianças.

Essas modificações exemplificam as possibilidades de reestruturação do habitus de cada professora diante do inusitado, oportunizando a realização de ações pouco presentes anteriormente nas suas rotinas.

\section{Dinâmicas de socialização}

$\mathrm{Na}$ análise dos dados foram percebidos impactos de alteração na dinâmica do 
trabalho das professoras em seu dia a dia, ou seja, suas atividades eram permeadas por um conjunto de relações sociais desencadeadas dentro de sala de aula, envolvendo as crianças.

No início, as crianças sofreram impactos com a presença dos colegas com deficiência incluídos no ensino comum. As crianças ficaram assustadas, e pudemos identificar tal impacto no depoimento da professora, no excerto relatado a seguir.

"[...] tem algumas crianças que estão assustadas ainda, mas, também, no primeiro dia de aula ela veio, as crianças ficaram assustadas [...]. (PROFESSORA 2)

A professora, ao verificar a ocorrência, pediu para a mãe trazer a menina um pouco mais tarde no dia seguinte, de modo que ela pudesse conversar com a classe sobre a deficiência da criança, os acontecimentos que nela deixaram seqüelas, seu tamanho e idade (12 anos) e por que ela estava sentada na primeira carteira quando os mais altos estavam atrás.

Havia, entre todas as professoras, uma preocupação inicial com a socialização das crianças incluídas no ambiente escolar, juntamente com seus pares, principalmente em sala de aula. Com a inserção, por exemplo, do aluno com deficiência intelectual na classe regular, a socialização de todos se altera, como se pode verificar nos excertos apresentados a partir das entrevistas:

"A relação da aluna com os outros alunos é muito boa.” (PROFESSORA 2)

"A inclusão de alunos foi uma parte que me chamou a atenção, eu achei muito legal, os alunos começaram a se entrosar dentro da classe normal.” (PROFESSORA 1)

"Eu acho que é hipocrisia da minha parte falar que ela é igual a todo mundo, ela sabe que ela não é igual [...] ela sabe que tem dificuldade, os alunos sabem, então não é para a gente tentar mascarar, nada disso [...] Ela entende que é diferente, não adianta falar que ela é igual a todo mundo, ela mesma sabe que é diferente." (PROFESSORA 2)

"Eu acho que se ela estivesse numa turma especializada, ela estaria com pessoas, com crianças com o mesmo problema dela, aí ela poderia ter melhorado na parte da fala, mas ela poderia não estar bem na parte da socialização.” (PROFESSORA 3)

Os depoimentos das professoras sobre a socialização das crianças são muito relevantes para o resultado educativo geral, considerando as possibilidades que essas situações trouxeram para a formação geral, pois as rotinas de muitas dessas crianças alteraram-se no que tange a contatos sociais. Algumas crianças já estavam na escola há dois ou três anos, sem convivência com crianças com deficiência; e estas também passaram de situações de segregação para outras de integração, “como orientação para que as ações educativas do ensino do aluno que possui um tipo de deficiência” (SOARES, 2006), vigentes anteriormente ao aparecimento das propostas de educação inclusiva no Brasil, sejam adequadas e promovam, de fato, a necessária inserção desse aluno na escola regular e na própria sociedade.

\section{Considerações finais}

As professoras, no seu trabalho em sala de aula com os alunos com deficiência incluídos no ensino comum, em função da ação política educativa estadual, consideravam difícil adequar-se à nova situação e conseguir fazer tudo o que precisavam diante do excesso de trabalho que lhes era exigido, já como decorrência de outras ações políticas 
de mudança implantadas quase simultaneamente. Talvez esse dado apareça com mais nitidez pelo fato de as professoras não serem consultadas e muito menos receberem apoio para a implantação dessa ação política aqui abordada e pelas condições de trabalho que vivenciavam.

Evidentemente, essa nova situação inesperada gera insegurança, medo e ao mesmo tempo motiva alguns professores a encontrar forças para enfrentar os conflitos, ao ter que abandonar antigas certezas - como, por exemplo, a de que a escolarização desse tipo de alunado tem que ser feita só por especialistas - e, então, assumir a nova situação. Por isso, pode-se afirmar que a inclusão dos alunos com deficiência nas salas de aulas observadas gerou impactos pessoais em cada professor, impondo desafios e levando-os a enfrentar os conflitos que ali se instalaram.

As esferas pedagógicas descritas neste texto permitem detectar alguns aspectos nos quais foram percebidos efeitos e reações relativos ao processo de inclusão de crianças com deficiência em sala de aula comum, cujas análises apontam que cada professor recebe a prescrição oficial de acordo com o que pensa, sente, a maneira como trabalha, ou seja, conforme seu habitus construído até então. As salas de aula observadas puderam ser vistas como lugares heterogêneos, com conflitos, erros, acertos e muita dedicação por parte das professoras. Vale destacar a disposição, presente em seus habitus, de refletir sobre seu próprio trabalho, analisar a situação que estavam vivendo para enfrentá-la, o que possibilitou o resultado aqui apresentado.

Essa imposição política, como tantas outras, causou impactos no trabalho docente das professoras pesquisadas. A falta de incentivo e de apoio fazia com que baseassem sua própria prática em um referencial pré- -existente, em práticas sedimentadas, rotineiras. Entretanto, os conflitos e as situações inusitadas vivenciadas levaram-nas a gradativamente alterar seu trabalho, com toda a complexidade das situações: novos procedimentos, novas escolhas de materiais, de relacionamento com os alunos, de avaliação, de providenciar explicações sobre a realidade que estavam vivenciando, passando a exercer ações peculiares. Foi possível presenciar características distintas nas ações docentes, a partir de práticas comuns. Constataram-se, também, mudanças em algumas disposições de seus habitus, ainda que tenham sido apenas naquelas turmas observadas, cuja análise nos permite compreender parte do que ocorre nessas circunstâncias.

\section{Referências}

BONNEWITZ, P. Primeiras lições sobre a sociologia de P. Bourdieu. Petrópolis: Vozes, 2003.

BOURDIEU, P. A gênese dos conceitos de habitus e de campo. In: . O poder simbólico. Rio de Janeiro: Bertrand Brasil, 1989, p. 59 - 74.

BRASIL. Lei n. 9394, de 20 de dezembro de 1996. Estabelece as diretrizes e bases da educação nacional. Disponível em: <http:// portal.mec.gov.br/seed/arquivos/pdf/tvescola/leis/lein9394.pdf>.

BRASIL. Ministério da Educação. Diretrizes nacionais para a Educação Especial na Educação Básica. Brasília: MEC; SEESP, 2001.

BRASIL. Ministério da Educação. Política nacional de Educação Especial na perspectiva da Educação Inclusiva, Brasília: Secretaria de Educação Especial, 2008. 
BUENO, J. G. S. Crianças com necessidades educativas especiais, política educacional e a formação de professores: generalista ou especialista. Revista Brasileira de Educação Especial, n.5, Piracicaba: UNIMEP, 1999.

. Educação Especial brasileira: integração/segregação do aluno diferente. 2. ed. São Paulo: PUC/SP - EDUC, 2004.

; MENDES, G. L.; SANTOS, R. A. (Orgs.). Deficiência e escolarização: novas perspectivas de análise. Araraquara: Junqueira \& Marin, 2008.

CORCUFF, P. As novas sociologias: construções da realidade social. Bauru: EDUSC, 2001.

ESPANHA. MINISTERIO DE EDUCACIÓN Y CIENCIA. Organización de las Naciones Unidas para la Educación, la Ciencia y la Cultura. Conferencia Mundial sobre Necesidades Educativas Especiales: acceso y calidad. España: Salamanca, 1994.

FERREIRA, V. M. R. A organização do trabalho pedagógico em escolas cicladas: ainda uma lógica “centrífuga-homogeneizadora”. In: SAMPAIO, M. M. F. O cotidiano escolar face às políticas educacionais. Araraquara: JM Editora, 2002.

GIMENO, J. Poderes inestables en educación. Madrid: Morata, 1998.

MARIN, A. J. Didática e trabalho docente. Araraquara: Junqueira \& Marin, 2005.

LUNARDI, G. M. Nas trilhas da exclusão: as práticas curriculares da escola no atendimento às diferenças do aluno. Tese (Doutorado). Pontifícia Universidade Católica de São Paulo. São Paulo, 2005.

MANTOAN, M. T. E. et al. Introdução. In: MANTOAN, M. T. E. A integração de pessoas com deficiência: contribuições para uma reflexão sobre o tema. São Paulo: Memnon: Editora SENAC. p.6-9, 1997.
MENDES, E. G.; ALMEIDA, M. A. (Orgs.). Das margens ao centro: perspectivas para as políticas e práticas educacionais no contexto da educação especial inclusiva. Araraquara: Junqueira \& Marin, 2010.

OLIVEIRA, M. A. da C. A educação de deficientes auditivos: uma proposta de intervenção. Dissertação (Mestrado). Pontifícia Universidade Católica de São Paulo. São Paulo, 1996.

. Práticas de professoras do ensino regular com alunos surdos inseridos: entre a democratização do acesso e permanência qualificada e a reiteração da incapacidade de aprender. 2005. 179p. Tese. (Doutorado em Educação: História, Política, Sociedade). Pontifícia Universidade Católica de São Paulo, 2005.

SAMPAIO, M. M. F. (Org.). $O$ cotidiano escolar face às políticas educacionais. Araraquara: JM Editora, 2002.

SASSAKI, R. K. Inclusão: construindo uma sociedade para todos. Rio de Janeiro: WVA, 1997.

SCHWARTZMAN, J. S. Integração: do que e de quem estamos falando? In: MANTOAN, M. T. E. (Coord.). A integração de pessoas com deficiência: contribuições para uma reflexão sobre o tema. São Paulo: MEMNON: Editora SENAC, 1997. p. 62-66.

SILVA, F. C. T. As relações entre ensino, aprendizagem e deficiência mental desenhando a cultura escolar. Tese (Doutorado). Pontifícia Universidade Católica de São Paulo. São Paulo: 2003.

SOARES, M.A. L. Aeducação do deficiente auditivo: reabilitação ou escolaridade? Dissertação (Mestrado). Pontifícia Universidade Católica de São Paulo. São Paulo, 1990. 
. Os processos de inclusão e exclusão das crianças ejovenssurdos comoestratégiade observação do trabalho escolar. In: FREITAS, Marcos Cezar (Org.). Desigualdade social e diversidade cultural na infância e na juventude. São Paulo: Cortez, 2006. p. 87109.

VIÑAO FRAGO, A. Culturas escolares, reformas e innovaciones: entre la tradición y el cambio. In: La construción de una nueva cultura en los centros educativos. Jornadas estatales del Forum Europeo de Administradores de la Educación, 8. Murcia, 1996, p. 18 - 29.

WOODS,P.Laescuelapordentro.Barcelona: Editorial Paidós, 1998.

Recebido em: 30/04/2012

Aceito em: 23/06/2012 